\title{
Correction to: Preparation and dielectric properties of PVP-based polymer electrolyte films for solid-state battery application
}

\author{
S. K. Shahenoor Basha ${ }^{1}$ - G. Sunita Sundari ${ }^{1}$. \\ K. Vijay Kumar ${ }^{2}$ M. C. Rao ${ }^{3}$ \\ Published online: 28 June 2019 \\ (c) Springer-Verlag GmbH Germany, part of Springer Nature 2019
}

\section{Correction to: Polym. Bull. (2018) 75:925-945 https://doi.org/10.1007/s00289-017-2072-5}

This erratum corrects the Fig. 3a, d of the published paper. The results presented in the published paper are correct and are not affected by the change in figures.

The authors regret for the change in figures.

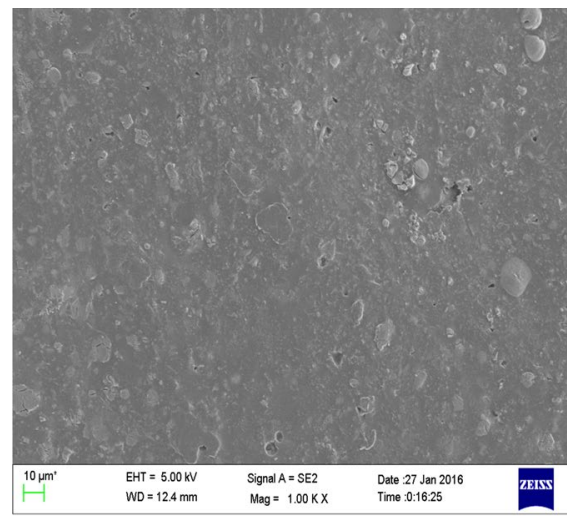

(a)

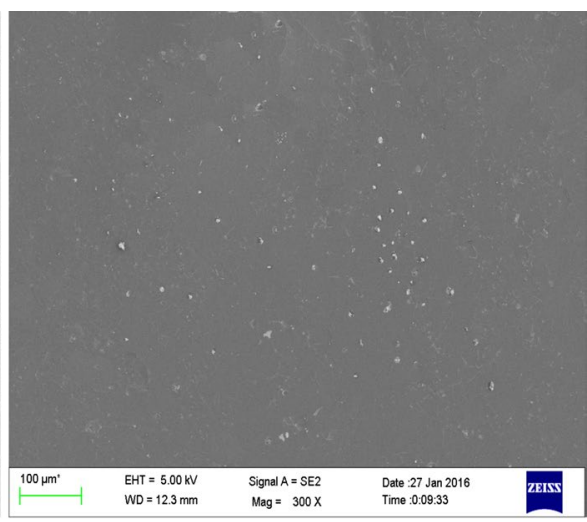

(d)

Fig. 3 SEM images of polymer electrolyte films for a pure PVP, $\mathbf{d}(85: 15) \mathrm{wt} \%$ ratio SPE

The original article can be found online at https://doi.org/10.1007/s00289-017-2072-5.

M. C. Rao

raomc72@gmail.com

1 Solid State Ionics Laboratory, Department of Physics, K. L. University, Guntur 522502, India

2 Department of Physics, Dayananda Sagar Academy of Technology and Management, Udayapura, Bangalore 560 082, India

3 Department of Physics, Andhra Loyola College, Vijayawada 520008, India 